\title{
ESCREVER, AUTORIZAR E CONHECER: UMA ANÁLISE DA RELAÇÃO ENTRE ESCRITA, AUTORIA E PRODUÇÃO DE CONHECIMENTO
}

\section{WRITING, AUTHORIZING AND KNOWING: AN ANALYSIS OF THE RELATIONSHIP BETWEEN WRITING, AUTHORSHIP AND KNOWLEDGE PRODUCTION}

\author{
Lúcio Álvaro Marques*
}

\begin{abstract}
RESUMO: A análise das formas de produção de conhecimento escondem verdades que determinam os escritos acadêmicos. A forma chega a prevalecer sobre o conteúdo. Com isso, a produção tanto gera efeitos pela mera instituição da forma quanto esconde estratégias que inviabilizam o desenvolvimento e manifestação da autoria nos escritos. $\mathrm{E}$, geralmente, o escondimento da autoria não se deve à objetividade do texto nem à neutralidade científica, mas às estratégias de anulação do autor. No ato de escrever, o emprego da terceira pessoa do plural e da forma acadêmica de citação e referenciação, não poucas vezes, visa esconder a autoria, mas não apenas isso. O problema torna-se notório à medida que o autor abdica da possibilidade de demarcar sua posição teórica por submissão às normas acadêmicas. Outro aspecto é aquele em que o autor não se deixa ver pela tentação de manter neutralidade ou objetividade científica. A questão que analisaremos, portanto, refere-se a alguns escritos de estudantes e à forma como os estudantes escondem-se por trás das citações para não se darem a conhecer na escrita. O corpus eleito tem "semelhanças de família" (repetições e diferenças) e por se tratar de um conjunto de artigos apresentados por estudantes dos períodos iniciais das licenciaturas da UFTM e, neste artigo, analisaremos um artigo que se tornou paradigmático por sua origem e organização temática. Nossa hipótese será demonstrar como o apagamento do sujeito não é responsabilidade do acadêmico, mas resultado da própria estrutura de produção de conhecimento.
\end{abstract}

Palavras-chave: Produção de conhecimento; Academia; Autoria; Normatização do saber.

ABSTRACT: The analysis of the forms of knowledge production hides truths that determine academic writings. The form comes to prevail over the content. Thus, the production both generates effects by the mere institution of form and hides strategies that make the development and manifestation of authorship in writings unfeasible. And, generally, the hiding of authorship is not due to the objectivity of the text or to scientific neutrality, but to the author's strategies of annulement. In the act of writing, the use of the third person plural and the academic form of citation and referencing, not infrequently, aims to hide authorship, but not only that. The problem becomes notorious

\footnotetext{
* Doutorado em Filosofia pela Pontifícia Universidade Católica do Rio Grande do Sul (PUC-RS). Docente da Universidade Federal do Triângulo Mineiro (UFTM).
} 
as the author relinquishes the possibility of demarcating his theoretical position by submitting to academic norms. Another aspect is that in which the author does not let himself be seen by the temptation to maintain neutrality of scientific objectivity. The question that we will analyze, therefore, refers to some students' writings and the way in which students hide behind quotations so as not make themselves known in writing. The elected corpus has "family resemblances" (repetitions and differences) and it is a set of articles presented by students from the initial periods of the UFTM licensures and, in this article, we will analyze an article that became paradigmatic due to its origin and thematic organization. Our hypothesis will be to demonstrate how the deletion of the subject is not the academic's responsibility, but the result of the knowledge production structure itself.

Keywords: Knowledge production; Academia; Authorship; Knowledge standardization.

O que se pode identificar enquanto produção de conhecimento e indício de autoria em escritos acadêmicos? A intenção neste texto é apresentar uma discussão sobre o lugar da escrita acadêmica na perspectiva filosófica tanto à luz das leis do discurso quanto da racionalidade imanente à própria escrita. Para tanto, recorremos À ordem do discurso e a O que é um autor? de Michel Foucault para explicitar tanto o sentido desses conceitos (autoria e produção acadêmica) quanto a tríade de princípios que regem a lógica da escrita, a saber: o autor, o comentário e a disciplina. Na primeira parte, consideraremos as leis do discurso e a lógica imanente em vistas de situar o que entendemos por indícios de autoria nominal ou formal-estrutural e para situarmos a função-autor segundo Foucault. Na segunda parte, analisaremos um artigo produzido por Emília (nome fictício), A violência doméstica e suas formas, procurando explicitar alguma possibilidade de produção de conhecimento na relação entre o texto estudado - a escritura e o comentário realizado pela autora. E, na terceira parte, situaremos algumas breves notas acerca da tensão entre novidade e originalidade na escrita acadêmica. O leitor não encontrará em nosso artigo uma leitura rigorosa da teoria foucaultiana sobre a escrita, pois reduzimos nossas referências exclusivamente à conferência programática de 1970. Porém, no horizonte desse texto, faremos relações, por um lado, com notas sobre a escrita presentes em Derrida (1991) e, por outro, sobre o sentido da leitura e escrita em Nietzsche (2004). Com isso, nossa hipótese de trabalho é a seguinte: considerando os limites impostos à forma, ao conteúdo e ao objetivo da escrita acadêmica, é 
possível reconhecer nessa escrita elementos comprobatórios de produção de conhecimento e quaisquer indícios de autoria?

\section{A FILOSOFIA ENTRE AS LEIS DO DISCURSO E A RACIONALIDADE IMANENTE}

A ordem do discurso é uma palavra inicial, mas registra uma série de projetos de estudos e também alguns resultados das pesquisas precedentes. Não a leremos na ordem em que o discurso foi construído, mas apenas pinçaremos elementos que saltam aos olhos à medida que pensamos as lógicas imanentes da educação. Começamos por uma questão em torno da educação, ou melhor, da educação pensada nos limites do sistema de ensino: "o que é afinal um sistema de ensino senão uma ritualização da palavra (...)?" (FOUCAULT, 2009, p. 44). Seria estúpido reduzir a educação ao projeto de ensino. A ação de educar precede e sucede qualquer sistema de ensino como o entendemos, porque esse sistema é datado e representa uma compreensão social enquanto promove determinados valores situados na sociedade de onde se origina. O sistema de ensino identifica-se tout court com a instituição escolar/universitário de ensino. Sua palavra é proclamada dentro de instituições disciplinares rigorosamente programadas para tal. Se considerarmos a estética das salas de aula, veremos facilmente que são dispostas verticalmente em direção à figura docente que ocupa, não raras vezes, uma posição de confronto (uma disposição frontal) oposta à dos estudantes e, por isso, os olhares já lhe estão naturalmente destinados. Se tivéssemos outra estética, por exemplo, com salas circulares, não teríamos um ponto de partida tão claro e limitante. Talvez favoreceria discursos mais circulares, interativos e dinâmicos, mas tanto no hemisfério norte quanto no sul, são comuns as disposições horizontal ou inclinada das salas de aula (tipo teatro), centrando os olhos dos estudantes na figura do professor e em (contra)disposição frontal. A estética já indica uma série de ritos e pressupostos, basta imaginar... Outras palavras são ditas de forma ainda mais explícita, afirmativa e proibitiva, como os sistemas de identificação e seleção de quem pode ou não entrar no recinto de ensino. A portaria centra a 
permissão na exposição do nome e dos códigos de identificação (número de matrícula, cadastro de pessoa física, registro geral, etc). Nesse e noutros dispositivos (biblioteca e laboratórios, por exemplo), a linguagem é perfeitamente ritualizada para permitir ou negar os acessos. O trânsito no sistema de ensino faz-se através da palavra, e o exemplo cabal encontra-se na mitologia branca (DERRIDA, 1991, p. 249-313). A metáfora do texto norteia a centralidade do sistema de ensino: lemos, explicamos, comentamos e exigimos que leiam e escrevam textos. Impresso ou digital, o sistema de ensino não se descola da magia do livro ou da mitologia branca e, nesse sentido, é impossível negar nossa logofilia (FOUCAULT, 2009, p. 50). Temos na mitologia branca a origem da informação, do conhecimento e o registro de experiências, verdades, ficções, catálogos, séries, fichamentos, estatísticas, etc., porque a codificação livresca do conhecimento ocupa o centro da transmissão de conhecimento em nosso sistema de ensino.

Nos projetos pedagógicos de curso, registramos uma ementa exígua e, no mínimo, oito exemplos míticos e os repetimos nos planos de ensino. Não podemos substituir livros por artigos. Podemos incluir, mas não substituir. Não podemos ensinar sem recorrer aos registros míticos dos experts, isto é, dos sabedores que escrevem livros e ensinam a ler, amar, estudar e reter os livros principais, isto é, mitologizamos nossos autores preferidos e suas obras como verdadeiros monumentos. $\mathrm{E}$, finalmente, somos infectados de logofilia: começamos a escrever e exigimos dos estudantes tanto essas leituras quanto que também mitifiquem, isto é, que também escrevam: eis a completa ritualização da palavra. Foucault parecia dispensar o direito à primeira palavra ao iniciar A ordem do discurso (2009, p. 5): "ao invés de tomar a palavra, gostaria de ser envolvido por ela e levado bem além de todo começo possível. Gostaria de perceber que no momento de falar uma voz sem nome me precedia há muito tempo..." Sim, Foucault tem razão: no princípio já era o verbo. O rito da palavra "precede e resume", de certa forma, todo o nosso sistema de ensino, e não se trata de qualquer palavra, mas da palavra similar à dos experts, de uma palavra autorizada e permitida. O resto é vetado ao silêncio ou, porque não, à ironia. Imaginemos, se para o próximo semestre letivo no Programa de Pós-gradução 
em Educação (PPGE), eu propusesse ofertar uma disciplina eletiva com esta ementa: "uma Disciplina de Irrelevância Comparada, onde se estudam materiais inúteis ou impossíveis (Tecnologia da Roda nos Impérios Pré-Colombianos, Iconologia Braille, Fonética do Filme Mudo...). A disciplina tende a reproduzir estudiosos de forma a aumentar ao infinito o número de matérias irrelevantes". Certamente, tanto o colegiado do PPGE aprovaria a ementa quanto haveria alguém a se matricular no curso?!

Se esta disciplina proposta não fosse apenas uma recordação d'O pêndulo de Foucault (2009, p. 84), escrito por Umberto Eco, eu merecia o prêmio de inventividade e um sonoro "não" do colegiado. Minha certeza decorre de um dado prévio: a disciplina proposta não obedece à ritualidade da palavra institucionalizada, tanto por insubordinação à "lei do discurso" quanto pela carência de uma "racionalidade imanente", porque todo discurso acadêmico "só promete a verdade ao próprio desejo da verdade e somente ao poder de pensála" e não à fantasia (FOUCAULT, 2009, p. 45). A fantasia, a imaginação, a inventividade, a irreverência, enfim, o cômico foram expulsos há muito tempo da universidade. Nela, o desejo de verdade se submete à disciplina do poder que coíbe tudo que se refere à não-verdade, à fantasia, ao imaginário. Quantos professores oferecem disciplinas sobre "a superioridade da mentira em relação à verdade"? (Oferecerei em breve na Faculdade de Irrelevância Comparada.)

Não somente ritualizamos a palavra quanto a subordinamos ao "valor de verdade" e a ameaçamos e/ou interditamos sob a ameaça da "disciplina do poder". A não-verdade está excluída do sistema de ensino e da ritualidade da palavra, por isso os livros e textos que propomos são - somente e exclusivamente - os livros e escritores autorizados pela praxe acadêmica. A ritualidade da palavra acadêmica seleciona os autores, higieniza os discursos dos professores e enquadra, formaliza, disciplina a palavra dos estudantes. Não há espaço para a fantasia e a mentira na academia (ao menos, em tese) e isso se deve aos "três princípios" mitologizados pelo sistema de ensino: o "do autor, do comentário e da disciplina" (FOUCAULT, 2009, p. 63), enfim, a mitologia branca ou o império da logofilia. Todo o discurso acadêmico já está previamente excluído da exterioridade selvagem e, ao mesmo tempo, obediente às regras e 
ritualidade do ensino (FOUCAULT, 2009, p. 35): "é sempre possível dizer o verdadeiro no espaço de uma exterioridade selvagem; mas não nos encontramos no verdadeiro senão obedecendo às regras de uma 'polícia' discursiva que devemos reativar em cada um de nossos discursos". Fora da "polícia discursiva" há espaço para a escrita no sistema de ensino? Como podemos despertar mentes inventivas se as disciplinamos através da obediência à "polícia discursiva"? Quantos se matricularão na Disciplina de Irrelevância Comparada?

Os três princípios enunciados por Foucault - o autor, o comentário e a disciplina - já estão disciplinados há tempos, tal qual a fala: "ela reduz a uma só figura todas as coerções do discurso: as que limitam seus poderes, as que dominam suas aparições aleatórias, as que selecionam os sujeitos que falam" (FOUCAULT, 2009, p. 37). A ritualidade do ensino não apenas fixa o direito de fala quanto interdita todos os discursos que queiram fazer frente à ritualidade "canônica" da academia. Ela interdita a palavra desautorizada e, ao mesmo tempo, policia a liberdade de pensamento. A ritualidade não quer outra coisa que reordenar a liberdade de pensar, por isso "a disciplina é um princípio de controle da produção do discurso. Ela Ihe fixa os limites pelo jogo de uma identidade que tem a forma de uma reatualização permanente das regras" (FOUCAULT, 2009, p. 36). A disciplina rouba a liberdade de tudo o que se lhe opõe mediante a política da coerção e castração da fala. Por isso, dificilmente poderemos ofertar disciplinas acerca da superioridade da mentira frente à verdade ou sobre a irrelevância comparada, embora saibamos que as fake news e as mentiras sociais determinem mais a vida da sociedade que propriamente os saberes acadêmicos.

Além da disciplina, o comentário constitui uma verdadeira "cláusula de barreira" na escrita acadêmica. Ele condiciona a escrita e o autor, uma vez que "o comentário limitava o acaso do discurso pelo jogo de uma identidade que teria a forma da repetição e do mesmo. O princípio do autor limita esse mesmo acaso pelo jogo de uma identidade que tem a forma da individualidade e do eu" (FOUCAULT, 2009, p. 29). O primeiro vértice da política da disciplina exprimese no comentário fixado nos dispositivos da repetição e da mesmidade. Qualquer 
professor de filosofia que entrega um texto de Hobbes ao seu público e pede um script ou uma reação crítica, dificilmente espera receber outro texto, senão um comentário sobre filosofia política e não um texto de ficção ou um romance. À medida que usamos em sala de aula um handout hobbesiano, nós o acrescemos de notas e citações de comentadores selecionados e fazemos "nossos comentários" com a atenção ou preocupação de "não desvirtuar o texto original". Somos demasiado fiéis e obedientes à obra que temos em mãos para comentar. Dificilmente admitimos que a obra de Hobbes suscitou uma OBRA por parte do que fizemos dela, porque pensamos a partir de uma subserviência acadêmica. Não nos damos o direito de criticar, senão mui respeitosamente os autores que temos em mãos. Com isso, o comentário final não passa além de repetição e mesmidade. Falta-nos a coragem de produzir a repetição e a diferença, parafraseando o título de Deleuze (1968). Nossos comentários dificilmente vão além de uma subserviente repetição e louvação dos autores ditos clássicos. E, neste ponto, impõe-se uma série de questões: como esperamos encontrar autoria nos trabalhos acadêmicos? Conseguimos superar a subserviência aos autores ditos clássicos? Ao escrever e produzir textos para uso acadêmico, priorizamos a criatividade e a inventividade ou repetimos e comentamos?

O segundo vértice da política da disciplina aponta a identidade do autor: "a forma da individualidade e do eu". E, neste ponto, as questões se multiplicam acerca do autorreconhecimento nos textos que escrevemos e publicamos. A saber, quando emitimos um parecer sobre um artigo científico, reconhecemos traços de autoria no texto ou um simples compilado de leituras de outros textos acrescidos de algumas informações gerais sobre a observação da realidade? Além de saber comentar bem um texto clássico e/ou sintetizar dados da observação empírica e cotidiana, um artigo científico revela indícios de autoria e reapropriação crítica de conteúdos? Quanto há de individualidade e de eu nos artigos que avaliamos? Como pareceristas para revistas, conseguimos perceber traços distintivos e/ou indicativos de estilo e possível autoria ou simplesmente a filiação teórica do autor?

Finalmente, a situação do autor e do comentário no organismo disciplinar permite-nos alguns deslocamentos. E quanto somos capazes de realizar? 
Vejamos como Foucault (2009, p. 30) os situa mais uma vez (com os itálicos que inserimos):

\begin{abstract}
A organização das disciplinas se opõe tanto ao princípio do comentário como ao do autor. Ao do autor, visto que uma disciplina se define por um domínio de objetos, um conjunto de métodos, um corpus de proposições consideradas verdadeiras, um jogo de regras e de definições, de técnicas e de instrumentos: tudo isto constitui uma espécie de sistema anônimo à disposição de quem quer ou pode servirse dele, sem que seu sentido ou sua validade estejam ligados a quem sucedeu ser seu inventor. Mas o princípio da disciplina se opõe também ao do comentário: em uma disciplina, diferentemente do comentário, o que é suposto no ponto de partida, não é um sentido que precisa ser redescoberto, nem uma identidade que deve ser repetida; é aquilo que é requerido para a construção de novos enunciados. Para que haja disciplina é preciso, pois, que haja possibilidade de formular, e de formular indefinidademente, proposições novas.
\end{abstract}

Sob o domínio disciplinar do objeto, do método, do corpus, das regras e das definições, das técnicas e instrumentos, quantos novos enunciados e proposições novas produzimos em nossa ação não só de comentadores, mas de autores? Com essa quantidade de interrogações levantadas até o presente, dificilmente chegaremos a outros lugares, pois creio que já estamos "condenados" por uma disposição prévia do sistema de ensino, isto é, somos submetidos à disciplina, ao comentário e ao reconhecimento de autoria, porque partimos de um conhecimento já instituído. Uma vez que reconhecemos Foucault ou algum outro autor como autoridade (mesmo que contra sua vontade!) na compreensão da escrita, a possibilidade de nos desvencilharmos dos limites do simples comentário está quase que previamente interditada, porque qualquer comentário que não seguir, rigorosamente, o texto original será interditado como uma espécie de heresia. Pensemos em quantas vezes ouvimos dizer que fulano não é um comentador fiel ou comentador recomendado para introduzir a obra de um autor. Isso somente acontece à medida que já canonizamos como correta a obra daquela autoridade e, com isso, só nos resta comentar e devolver o texto à sua "verdade original". Tudo o que desvia da interpretação tida por canônica soa como superinterpretação ou não será tratado como comentário sério. Nesse sentido, temo que indício de autoria e produção 
de conhecimento, ou seja, (re)apropriação e aplicação de conceitos em outros universos sejam desconsiderados na nossa praxe acadêmica.

Antes de passarmos à análise da relação entre escrita e produção de conhecimento, necessário se faz elencarmos indícios de autoria. Esta não se confunde com originalidade nem com novidade. A novidade trata, em termos acadêmicos, de conteúdos inéditos e/ou inexplorados de forma suficiente. A originalidade refere-se à capacidade de captar e evidenciar relações inauditas ou não-evidentes ao público. Certamente, concordamos que o mito da caverna de Platão não constitui novidade para nenhum leitor. Mesmo para quem pouco se dedicou à filosofia no ensino médio, já tem alguma informação ou conhecimento a seu respeito, por isso não é uma novidade. Não obstante, não é raro reconhecer que há filósofos que encontram formas inauditas e promissoras na interpretação desse mito. O aporte de uma interpretação rigorosamente original não pressupõe novidade, apenas uma capacidade de reconstruir o significado do mito, situando-o no horizonte hermenêutico que o torna portador de valores e significados até então ignorados. Por sua vez, a autoria aponta na direção da presença, ainda que um pouco diáfana, da voz e da identidade do autor no texto. Penso que a autoria tem dois níveis: o primeiro é explícito e reconhecível no uso do tempo e desinência de número e pessoa do verbo. O exemplo encontra-se no verbo empregado no início do período anterior - penso - que identifica o tempo presente, o modo indicativo e o eu como agente do pensar. O segundo é implícito e reconhecível apenas na criptoleitura do escrito, a saber: identifica-se o autor a partir das opções teóricas e da forma de argumentação. Neste segundo aspecto, precisamos reconhecer os autores implícita e explicitamente, a forma de redação ou o modo de textualizar e o interesse subjacente à escrita. De forma explícita e em miúdos: quanto aos autores, quem ler este artigo saberá que o autor aprecia, de algum modo, a filosofia francesa contemporânea por ter optado por ela como fonte de diálogo e preteriu, como poderia ser o caso, o diálogo com a linguística germânica ou norte-americana. Quanto à forma de redação ou modo de textualizar, obviamente, não se trata de uma escrita barroca com seus longos períodos (não obstante a extensão dos parágrafos) nem de uma escrita escolástico-medieval 
com as análises em forma de questões disputadas. Ao contrário, é um texto datado, em que se reconhece facilmente o interesse subjacente à escrita. É um work in progress e, nesse sentido, parece-se a um paper que já foi apresentado no ciclo de debates do Grupo de Estudos, Pesquisas em Análise do Discurso, Leitura e Escrita (GEPADLE) e agora ganha uma forma mais acabada, graças à colaboração dos colegas naquele debate ${ }^{1}$. Desta forma, temos dois indícios de autoria - uma nominal - indicada na primeira forma pelos verbos e suas flexões, e outra formal ou estrutural - identificada através das opções teóricas e das decisões retóricas do autor.

Dito isso, avancemos mais dois passos: primeiramente, bom recordar que não temos pretensão de explicitar os indícios formal ou estrutural no texto que analisaremos, porque trata-se de um trabalho acadêmico para avaliação conclusiva de uma disciplina e que os livros a serem lidos já estavam indicados previamente, logo Emília "não teve a liberdade" de selecioná-los, embora tenha escolhido trabalhar a partir deles e não de outros. Indício formal ou estrutural aplica-se de forma mais adequada a obras já publicadas e não trabalhos acadêmicos, pelas circunstâncias que lhe são próprias. Mas, o indício nominal, sobretudo indexado em ocorrências de pronomes pessoais e em flexões verbais, é bem mais fácil de ser identificado. Essa é a tarefa que nos propomos: reconhecer indícios nominais de autoria em $A$ violência doméstica e suas formas, artigo de Emília, licencianda em Química na UFTM.

Não obstante o objetivo de indiciar a autora esteja presente, cumpre lembrar com Foucault que "o sujeito que escreve despista todos os signos de sua individualidade particular; a marca do escritor não é mais do que a singularidade da sua ausência; é preciso que ela faça o papel do morto no jogo da escrita" (FOUCAULT, 2001, p. 270). Por isso, talvez seja tão difícil indiciar um autor. Ao mesmo tempo, cumpre recordar que essa é uma ação imputativa ou

\footnotetext{
${ }^{1}$ Agradeço as excelentes observações apresentadas na reunião do GEPADLE que contribuíram largamente para o aprimoramento deste debate. Destaco, sobretudo, as observações do professor Danilo S. Kato e da professora Janaína Zaidan B. Fonseca que espero ter integrado nesta versão do texto. À Janaína Zaidan agradeço ainda a indicação dos textos foucaultianos sobre a autoria, visto que não os tinha explorado na versão inicial deste artigo. Quanto à distinção entre originalidade e novidade, veja-se a leitura da parte referente à distinção dessa questão em The Jesuit Philosophical Heritage in Brazil (Marques, 2020).
} 
acusatória bastante séria. Não por acaso, Platão concluiu a Carta // (2002, p. 22) retirando quaisquer pistas de sua individualidade e autoria:

\begin{abstract}
Reflete, então, sobre isso e toma cuidado em não ter que te arrepender um dia do que deixarias hoje divulgar-se indignamente. A maior precaução será não escrever, mas aprender de cor... tò me gráphein all'ekmanthánein... pois é impossível que os escritos não acabem por cair no domínio público. Por isso, para a posteridade, eu mesmo não escrevi sobre tais questões... oud'éstin súngramma Platônos oudèn oud'éstai, não há obra de Platão e jamais haverá uma. O que atualmente designa-se sob esse nome Sokrátous estin kaloû kai neoû gegónotos... é de Sócrates no tempo de sua bela juventude. Adeus e obedece-me. Tão logo tenhas lido e relido esta carta, queima-a.
\end{abstract}

Que Platão seja um case of studies não há dúvida e talvez seja o maior de toda a história mundial, porém que ele não seja autor do Corpus Platonicum é tão curioso quanto surpreendente. Independente da procedência desse fato que mereceria uma longa análise sobre a parresía do mestre da verdade, a citação evidencia a afirmação foucaultiana: o autor parece querer evadir-se da cena do crime, ou melhor, da escrita. E não por acaso, Foucault afirma que "a função-autor está ligada ao sistema jurídico e institucional" (2001, p. 283). Descortinar o autor é ato jurídico, à medida que indexa a identidade de escritor aos indícios de sua linguagem, e ato institucional, porque o remete ao lugar em que fala e a partir de onde fala, isto é, que função desempenha na instituição. Um texto brilhante se for escrito por um estudante sequer será aceito para avaliação em alguns periódicos, o que torna evidente que a função-autor pautase mais pelo reconhecimento institucional (uso de título doutoral) que reconhecimento da competência conteudística. "A função-autor é, portanto, característica do modo de existência, de circulação e de funcionamento de certos discursos no interior de uma sociedade" (FOUCAULT, 2001, p. 277). Se o pretenso autor tem o direito de usar o dístico doutor, seu texto é avaliável no periódico, caso contrário, já está descartado a priori. Foucault indicia o autor como uma função situada dentro dos sistemas jurídico, institucional e social, mas não só. Há também a posição específica que se ocupa como escritor. $O$ contraexemplo clássico são algumas palestras de renomados escritores que, simples e cabalmente, não entendemos sequer o que queriam dizer com tudo $o$ 
que verbalizaram. Porém estavam investidos de uma posição que lhes atribuía autoridade. $\mathrm{O}$ autor somente funciona como tal se lhe for atribuída autoridade, isto é, poder e reconhecimento. Quantos professores foram contemporâneos de Foucault e Nietzsche e que talvez tenham escritos igualmente produtivos, mas que os desconhecemos quase completamente. Pensemos os exemplos de Nietzsche e Husserl: enquanto aquele sequer foi aceito na docência, este praticamente não teve suas obras publicadas enquanto vivia e até os nossos dias. Quem Ihes concedeu ou recusou autoria/autoridade? Como o sistema de ensino produz autoria?

\begin{abstract}
Eu os resumirei assim: a função-autor está ligada ao sistema jurídico e institucional que contém, determina, articula o universo dos discursos; ela nasce se exerce uniformemente e da mesma maneira sobre todos os discursos, em todas as épocas e em todas as formas de civilização; ela não é definida pela atribuição espontânea de um discurso ao seu produtor, mas por uma série de operações específicas e complexas; ela não remete pura e simplesmente a um indivíduo real, ela pode dar lugar simultaneamente a vários egos, a várias posições-sujeito que classes diferentes de indivíduos podem vir a ocupar. (FOUCAULT, 2001, p. 283)
\end{abstract}

No interior dos sistemas jurídico, institucional, social e da posição de classe, pode-se talvez supor que a função-autor seja mais uma questão de poder que propriamente de coerência teórica e rigor compreensivo acerca da realidade. Não é incomum um brasileiro conhecer a opera omnia de autores estrangeiros, mas nunca ter lido autores nacionais. Quem conhece as entediantes Confissões de Agostinho, as naturalistas Confissões de Rousseau e as eróticas Confissões de Darcy Ribeiro? Independente das opções teóricas, garanto que se divertirão e aprenderão infinitamente mais sobre si mesmos com a prosa mineira. Vejamos outros exemplos. Não é incomum reconhecermos que a juventude atual é avessa à leitura e arredia ao conhecimento, aliás, já é comum um qualquer dizer que na universidade pública é só balbúrdia e maconheiros, por isso confrontemos essas afirmações com as que se seguem:

Os jovens de hoje são mais devassos do que nunca, vestem-se de forma extravagante, regalam-se em banquetes e outros tipos de libertinagem, e, uma vez que não possuem empregos, desperdiçam tempo e dinheiro em jogos e mulheres; sua principal matéria de estudo 
é como se vestir de forma esplêndida e alcançar uma perspicácia absoluta em seu discurso (MAQUIAVEL, 1525, VII,5).

Maquiavel registrou essas palavras em sua História de Florença em 1525 e que autoridade Ihe atribuímos até nossos dias? Senão ao contrário, pode-se claramente dizer que tais palavras representam um preconceito comum que perdura por séculos, salvo raro engano. Essa autoridade deveria ser confrontada àquele um que falou de balbúrdia, mas também a esta outra consideração valorativa:

Provavelmente foi só no Brasil e na Tunísia que encontrei nos estudantes tanta seriedade e tanta paixão, paixões tão sérias e, o que mais me encanta, a absoluta avidez de saber (FOUCAULT, La philosophie structuraliste permet de diagnostiquer ce qe'est 'aujourd'hui', in Dits et écrits I, 584 apud MUCHAIL, 2004, p. 117-8)

Há três expressões distintas: Maquiavel parte de um princípio aristocrático para avaliar a degradação moral e social de Florença no século dezesseis. Aquele outro falava tudo o que Ihe vinha à mente sem nenhum critério, talvez em virtude de sua incapacidade reflexiva. Finalmente, Foucault conheceu a juventude brasileira e tunisiana como docente e, considerando a dimensão que nos é própria neste espaço universitário, quem deveria ser conhecido como autoridade? Quanto à universidade brasileira, quem infelizmente detinha poder e Ihe fez tanto mal? Que tipo de análise ou qual é o perfil interpretativo que atribuímos aos jovens estudantes? A quem consideramos como autoridade nessa questão?

Considerando o que denominamos indícios nominais de autoria, pode-se entrever o perfil autoral de Emília em $A$ violência doméstica e suas formas, pois na introdução já saltam aos olhos as flexões verbais na primeira pessoa do plural: "tentaremos compreender um pouco dessa realidade dolorida, com base nas reflexões apresentadas no Leviatã de Thomas Hobbes, além de referências a outros filósofos". Além do primeiro verbo indicar o propósito da autora, talvez a expressão dessa realidade dolorida possa soar como algo de possível experiência pessoal, ainda que indiretamente enunciado. Na sequência, uma decisão metodológica revela seu interesse: "para compreender tudo isso 
dividiremos esta exposição em cinco tópicos". E, na mesma sequência, há outro possível indício do lugar de fala da autora em relação à violência doméstica: "...por último, trataremos dessa sociedade sem escrúpulo que, recorrentemente, julgam as mulheres de todas as formas, desvalorizando-as, ao ponto de as mulheres, com as mesmas qualificações de um homem ou até melhores, ganharem menos que os homens, na mesma profissão". Emília sabe que se trata de uma sociedade marcada pelo machismo e com padrão moralista exacerbado. Eis um novo indício de sua posição, enquanto mulher e autora, dentro dessa sociedade.

Outros indícios nominais são reconhecidos no quarto tópico - o amor doentio - em que há não só a forma verbal, mas um raro pronome pessoal (todos os textos maiores de Emília aparecerão dentro de caixa para não se confundir com citações):

Isso nos leva a crer que a violência doméstica é um inimigo silencioso. O lar deveria ser de aconchego, amor, proteção, contudo não é isso que acontece, muitas vezes, quando os "chefes" da casa são contrariados, em vez daquilo, proporcionam dor, medo, insegurança, vergonha (NUNES; TONON, 2016).

Essa referência é a mais significativa, pois indica o universo simbólico da autora - isso nos leva a crer - em contraste com a representação mental que tem da casa: o lar deveria ser... contudo não é isso que acontece... Essa expressão mostra, primeiramente, a discordância entre imaginário doméstico, da casa/lar, e a contradição talvez com efetiva experiência histórica da autora. Se relemos todo o período, emerge outra contradição: "o lar deveria ser de aconchego, amor, proteção, contudo não é isso que acontece, muitas vezes, quando os "chefes" da casa são contrariados, em vez daquilo, proporcionam dor, medo, insegurança, vergonha (NUNES; TONON, 2016)". Embora partindo de uma referência científica, a autora contrasta aquilo que deveria ser o lar aconchego, amor, proteção - com o que acontece (seria sua experiência histórica?): "quando os 'chefes' da casa são contrariados, em vez daquilo, proporcionam dor, medo, insegurança, vergonha". A representação do chefe da casa (e não do lar) é bastante significativa, ainda mais aliada aos efeitos que 
proporciona: dor, medo, insegurança, vergonha. Mesmo em meio à trama argumentativa e científica, emergem indícios de autoria. Tais como os seguintes indícios manifestos pelos verbos e pela resposta à questão que não se liga diretamente à citação científica, por isso talvez indique mais uma vez um indício de autoria:

Quando procuramos o significado da palavra amor, encontramos que é um sentimento de carinho e demonstração de afeto, necessidade de proteção e de diversos cuidados diferentes. Por isso, quais são os motivos de os homens se acharem donos de suas companheiras? (...) Os homens usam todas as suas artimanhas para terem suas esposas como posses.

Talvez a resposta apresentada seja mais uma expressão da autora que algo cuja preocupação inicial fosse uma constatação científica. Finalmente, no quinto tópico sobre a sociedade machista há dois destaques significativos:

Um dos principais motivos de ainda haver violência doméstica deve-se ao fato de (OLIVEIRA; CAVALCANTI, 2007 p. 43) “[..] considerar as mulheres como sujeitos com consciência mediatizada pela ideologia machista", melhor dizendo, que as mulheres não são solidárias com as mesmas e, por consequência, colocam a culpa nas vítimas. (...) Somos uma sociedade machista e, para que isso mude, precisa-se de mulheres, reformulando as leis e, consequentemente, punindo mais severamente os abusos.

Tanto a acusação de falta de solidariedade quanto a assimilação da culpa revelam a verdadeira face do machismo que graça na sociedade e que, de alguma forma, passou a fazer parte da consciência de "certo imaginário feminino". O último destaque causou-nos um espanto ao ler, vejamos: somos uma sociedade machista e, para que isso mude, precisa-se de mulheres...Nosso espanto provém da situação em que a autora se coloca: por que ela situa-se dentro, ou como parte da sociedade machista? Ela seria machista, senão, por que usa o somos? E por que se refere às mulheres de forma impessoal: precisase de mulheres? Estou enganado ou ela não se inclui entre as mulheres responsáveis pela mudança social e reformulação das leis e, ao contrário, incluise como parte - somos - de uma sociedade machista²?

\footnotetext{
2 É provável que este seja um exemplo típico da neutralização da categoria da pessoa pelo processo de embreagem actancial na passagem da terceira pessoa à primeira do plural (FIORIN,
} 
Certamente, nossa intenção não é determinar o lugar do discurso da autora, menos ainda forçar indícios e/ou identificações que, por ventura, ela poderia recusar. A leitura dos indícios de autoria apenas apontam, mas não determinam ou não pretendemos dizer a última palavra sobre a questão. Porém, suspeitamos que a autoria deixa-se entrever nas expressões destacadas. Doravante, provoco o leitor a considerar e seguir a leitura, além de considerar a (re)apropriação elaborada por Emília em um artigo escrito como requisito avaliativo para uma disciplina de graduação na licenciatura em Química na UFTM.

\section{A PRODUÇÃO DO CONHECIMENTO ENTRE A ESCRITURA E O COMENTÁRIO}

Em primeiro lugar, devemos lembrar que o artigo de Emília foi escrito como requisito para avaliação disciplinar. A estudante poderia não escrever, mas seria reprovada. Logo, essa escrita está determinada a responder às demandas disciplinares de avaliação de conteúdo. Além disso, o conteúdo disciplinar já estava previamente organizado e aprovado pelos colegiados de curso e departamento e incluído como disciplina obrigatória em um PPC. Certamente diferiria se a estudante houvesse se matriculado em uma disciplina eletiva, em cujo conteúdo já possuísse alguma afinidade ou interesse prévio. Porém, foi o exato oposto que ocorreu. Antes de elaborar o artigo, solicitou o aproveitamento de outra disciplina (e foi indeferido) para não ter que cursar a disciplina obrigatória em questão (Filosofia e Política). A disciplina no PPC já apresenta ementa e bibliografia prévias, e a liberdade de que todos dispunham era optar entre dois exercícios avaliativos escritos ou um artigo. Optaram pelo segundo e, nesse caso, poderiam escolher um autor e uma obra como base para elaborar o artigo. O docente elencou um rol com três áreas de concentração - Saber, Poder e Estética - e em cada área constam cinco autores e obras, respectivamente, para livre escolha dos membros da classe. Emília escolheu o Leviatã de Thomas

1994/1995, p. 90). A questão não é mesmo relevante para uma análise mais detida, mas não o faremos agora por questão de tempo e espaço, uma vez que alargaria demasiadamente o escopo deste artigo. 
Hobbes, inscrito na seção Poder de análise temática de conteúdo. A estudante do segundo período somente "ouviu falar" de Hobbes vagamente no ensino médio e sabia que o homem é o lobo do próprio homem, atribuindo a frase de Plauto à suposta autoria hobbesiana.

A versão final do artigo entregue para avaliação apresentava uma introdução com pouco mais de uma página, cinco subtópicos totalizando nove páginas, uma conclusão de meia página (catorze linhas) e dezesseis referências bibliográficas, com o total de doze páginas. A diferença de extensão entre introdução e conclusão é notória, pois a estudante retomou os tópicos centrais do texto condensando-os de forma sumária, embora pudesse (e isso era facultado aos membros da turma) expressar na conclusão inclusive sua (in)satisfação quanto às leituras realizadas para elaboração do texto. Poderiam expor sua empatia ou antipatia quanto ao lido. Consideremos detidamente as partes do artigo.

Emília elaborou o artigo $A$ violência doméstica e suas formas a partir das leituras d'O príncipe de Maquiavel e do Leviatã de Hobbes, como consta na bibliografia e como anunciado, quando fez o envio do texto por correio eletrônico. Note-se também que o uso dos filósofos de forma "tolerante" foi destacada na primeira nota de rodapé como recurso à sugestão de consultar alguns comentadores para entender as obras em questão. Introduz o conteúdo e, de certa forma, resume o artigo em poucas palavras presentes na introdução:

Tentaremos compreender um pouco dessa realidade dolorida, com base nas reflexões apresentadas no Leviatã de Thomas Hobbes, além de referências a outros filósofos. Algumas questões pertinentes como: o medo e os índices de violência doméstica, o amor doentio e a sociedade machista coexistem com institutos sociais que lutam para punir os agressores e apoiar as vítimas da violência doméstica.

A discussão do medo nas obras de Maquiavel e Hobbes refere-se à gestão social baseada, por um lado, no medo que a sociedade deve ter da ação e do poder do príncipe e, por outro, no medo que produziu o parto prematuro de Hobbes mediante a deflagração da guerra e que ele reelaborou enquanto estratégia política para controle da sociedade. O uso que a autora faz desse conceito vincula-se à "violência doméstica, ao amor doentio e à sociedade 
machista". Qualquer comentador de Maquiavel e Hobbes diria que ambos estavam preocupados com a "organização do Estado social" e não primeiramente com a violência doméstica. Questão inaudita àqueles tempos. A estratégia da autora foi incluir a nota "fizemos um 'uso tolerante' dos conceitos filosóficos, isto é, nossa intenção primeira era estudar o tema do medo como elemento de domínio social e terminamos chegando ao medo na estrutura da vida familiar..." A leitura proposta extrapola bastante o interesse dos filósofos e das obras em questão, porém seria uma apropriação indevida?

No primeiro tópico, apontam-se índices de violência contra mulheres tanto a partir do Sistema de Vigilância de Violências e Acidentes (VIVA/SINAN) quanto do Centro de Estudos Jurídicos (CEJ) e outros autores, excluindo-se referências mais pessoais. A seguir, o tópico Lei Maria da Penha restringe-se a uma breve descrição da violência sofrida por Maria da Penha Maia Fernandes e indica o surgimento do Instituto e da Lei que trazem seu nome. O terceiro tópico sim, apresenta uma redação mais extensa e pessoal sobre o medo no terceiro parágrafo desse texto:

\footnotetext{
Para Hobbes (2017, p. 71), “a paixão cuja violência ou continuidade produz a loucura é uma grande vanglória, que comumente é chamada orgulho e autoestima ou depressão da mente". Os violentadores sentem-se no direito de humilhar, com torturas psicológicas e, até mesmo, físicas, às vezes diante de outras pessoas, mostrando o seu poder. Essas mulheres sempre ouvem (HOBBES, 2017, p. 58): o "amor particular por alguém, com desejo de ser reciprocamente amado, é paixão amorosa. O mesmo, porém, cercado de dúvidas de que haja reciprocidade, é ciúmes”, fazendo que elas se sintam culpadas de alguma forma, levando em consideração o ditado que diz: quem ama, cuida.
}

O uso dos textos filosóficos selecionados para confirmar as opções de Emília têm em Hobbes uma semelhança de parentesco teórico, embora o autor não tivesse tratado das relações familiares. Hobbes refere-se às relações sociais e às forças que moldam e movem as decisões políticas. Essa situação torna-se ainda mais visível no emprego do texto de Maquiavel no meio do quarto parágrafo, em que se registra: 
Essas mulheres tentam fazer como o Maquiavel diz no Príncipe (2012, p. 17) "se quiserem agir com lealdade encontrarão mais razão para amá-lo; e, se tiverem a inclinação ao contrário, terão mais motivos para temê-lo". Isso nos leva a crer que a violência doméstica é um inimigo silencioso. O lar deveria ser de aconchego, amor, proteção, contudo não é isso que acontece, muitas vezes, quando os "chefes" da casa são contrariados, em vez daquilo, proporcionam dor, medo, insegurança, vergonha (NUNES; TONON, 2016).

O amor e a lealdade destacados por Maquiavel referem-se ao amor dos súditos pelo príncipe. Aqueles deveriam temê-lo mais que amá-lo, pois quem ama trai e pode ser infiel, ao passo que quem teme a fúria da violência do príncipe jamais ousará afrontá-lo, visto que sabe como ele pune a traição: com a morte dos súditos insubordinados. Não obstante, Emília emprega a descrição maquiavélica para pensar as relações doentias entre os casais. A autora passa de uma afirmação clássica de Maquiavel (1469-1527) sobre o uso da força e do poder pelo príncipe à afirmação: "isso nos leva a crer que a violência doméstica é um inimigo silencioso". A distância entre o projeto maquiaveliano de unificação da Itália e "recente discussão" (visto que historicamente só no século vinte a violência doméstica entrou para a pauta de discussão) e a violência doméstica parecem inconciliáveis, e Emília escreve - isso nos leva a crer... Nesse sentido, quem leu o texto deveria dizer que ela fez uma "superinterpretação" ou uma distorção do texto de Maquiavel ou deveria aceitá-lo como uma apropriação livre, um uso tolerante do original? O que, classicamente, constituiria um desvio e/ou deslocamento interpretativo, um ato de superinterpretação, no sentido de Richard Rorty: um uso abusivo e desinteressado do sentido original do texto empregado (ECO, Interpretação e superinterpretação). Esse seria um comentário infiel ao texto que não é capaz de manter a repetição e mesmidade do original. No entanto, seria isso um desvio indevido ou se deveria manter a ortodoxia? Pode-se pensar a produção de conhecimento como (re)apropriação e derivação ou livre interpretação do texto inicial ou a fidelidade ao texto sobrepõe-se às possibilidades de assimilação? O comentário deve necessariamente se manter nos limites da repetição e da mesmidade do escrito original em estudo? A forma como Emília realiza o comentário do texto clássico 
(o comentário à escritura inicial) caracteriza uma produção de conhecimento ou simples comentário infiel ao original?

A estratégia argumentativa da autora permanece até o final do artigo. Além da parte final do terceiro tópico, há mais dois tópicos em que reaparecem comentários aos textos de Maquiavel e Hobbes e que merecem leitura como forma de exemplo e proposta de discussão:

Segundo Hobbes $(2017$, p. 48) “[...] esses homens não fazem outra coisa senão tomar como razão verdadeira as paixões que os dominam, revelando sua carência de verdadeira razão pela ostentação que dela fazem". Quando a mulher aceita os argumentos do seu marido sem questionar, ou seja, confiando que ele realmente está certo, ela perde seu tempo, pois isso prova que ela ainda não compreendeu a real situação. Ela simplesmente acredita nele, e se submete a diversas situações constrangedoras. Embora com o pensamento, que ele faz isso para o seu bem.

$O$ argumento de Hobbes refere-se às relações humanas no âmbito da vida política e não às relações matrimoniais em primeiro lugar. Aliás, essa não era uma preocupação hobbesiana. A irracionalidade das paixões e ações humanas destina-se à compreensão da luta de forças na sociedade para instituição de um Estado capaz de ordenar os súditos. Emília interpreta o texto em função da compreensão familiar entre homem e mulher e nas formas da vida privada. Hobbes pensa as relações humanas públicas, e Emília interpreta os textos em função da vida privada. A apropriação caracteriza produção de conhecimento ou "um 'uso tolerante' dos conceitos filosóficos"?

No quarto tópico - o amor doentio - ela retoma uma passagem que trata o desejo e o amor enquanto paixões que agem na organização da vida pública e transpõe esses argumentos para a vida privada, como se lê: 
O sentimento de impotência torna-se maior, pois precisam abdicar do seu bem-estar, para dar um teto aos seus filhos, mesmo passando por tanta humilhação sem nenhum apoio. Tal como podem-se entrever em mais uma referência ao Leviatã: "Do que os homens desejam se diz também que o amam, e que odeiam aquelas coisas pelas quais sentem aversão. De modo que o desejo e o amor são a mesma coisa, salvo que por desejo sempre se quer significar a ausência do objeto, e quando se fala em amor geralmente se quer indicar a presença do mesmo. Também por aversão se significa a ausência, e quando se fala de ódio pretende-se indicar a presença do objetivo" (HOBBES, 1979, p. 32). Para Hobbes, o homem é mau em estado de natureza. Estado em que o ódio se perpetua em suas atitudes e, como consequências, desconta na sua companheira ou na colega de trabalho, pois as consideram como inferiores, e isso pode ser visto em vários locais. Desde do trabalho, onde a maioria dos cargos de confiança são preenchidos por homens, até mesmo na política, a maioria são homens. Somos uma sociedade machista e, para que isso mude, precisa-se de mulheres, reformulando as leis e, consequentemente, punindo mais severamente os abusos.

O último tópico - sociedade machista - mantém a mesma lógica argumentativa tanto na reapropriação livre do texto quanto na formulação de seu comentário: há uma transição da argumentação em torno da vida pública à vida privada, sem destaque prévio. Além da transição da citação de Hobbes às referências a outros autores que não estão lendo o filósofo, finalmente, a última passagem demonstra como há uma indistinção entre o texto de Hobbes e as referências que o mesmo faz aos outros textos. Na verdade, Emília refere-se a Hobbes em uma mentalidade comum, refletindo uma interpretação corriqueira sem maior explicitação:

Diversas pesquisas apontam que a maioria da população é feminina, então, quais são os motivos da existência de uma sociedade patriarcal? Para Hobbes (1970, p. 53), "o poder de um homem consiste nos meios de que representa e dispõe para obter qualquer visível bem futuro", ou seja, a minoria dita as regras, melhor dizendo, os homens ditam as regras e a sociedade segue. A partir de onde se inicia a idealização da imagem de esposa: por um lado, obediente ao seu marido, fiel, apesar de traída e, por outro lado, a valorização de habilidades masculinas como a de controlar a esposa e corrigi-la quando necessário. São condicionamentos sociais, de onde se segue um padrão que não deve sofrer alteração, e alicerçada pelo aparelho ideológico do patriarcalismo, determinando identidades e valores tanto para homens como para as mulheres (OLIVEIRA; CAVALCANTI, 2007). Hobbes popularizou a expressão o homem é o lobo do próprio homem, ou seja, somos pessoas egoístas e não sentimos bem com a felicidade alheia. Isso explica pessoas com "o desejo de fazer mal a outrem, obrigando-o a lamentar algum fato ocorrido, é afã de vingança” (HOBBES, 2017, p. 58).

O elemento final presente na conclusão destaca-se tanto pela fuga ao comentário pessoal quanto pelo retorno ao âmbito da responsabilidade pública: "diante de todos os argumentos apresentados, lembrando com Hobbes que a 
liberdade é ausência de oposição, cabe ao governo organizar a sociedade para que isso ocorra, garantindo assim liberdade a todas as pessoas, ou seja, igualdade para todos e todas". A autora não apresenta uma formulação pessoal na conclusão e mais, devolve a responsabilidade ao espaço público: cabe ao governo organizar a sociedade. Parece-me um retorno à argumentação do poder público como gestor das relações sociais, enquanto a temática em debate - a violência doméstica - parte do âmbito da vida privada. Obviamente que se trata de um caso de violência que toda a sociedade e o poder público precisam restringir, porém a argumentação da autora estava quase que restrita à vida privada.

\section{O CONHECIMENTO ENTRE A NOVIDADE E A BUSCA DE ORIGINALIDADE}

Todas essas notas estão apresentadas apenas para discussão. A bem da verdade, conservo ainda um forte tom cético quanto aos conceitos de produção de conhecimento, novidade e originalidade em termos de escrita acadêmica. Entendendo essa escrita como a elaboração de textos, artigos, dissertações e teses e retomando a tríade de princípios que Foucault anuncia - o autor, o comentário e a disciplina - não imagino como nem o autor, enquanto individualidade e eu, nem o comentário, enquanto repetição e mesmidade, facultam alguma emergência de novidade ou originalidade. Ademais, a novidade não se refere à irrupção de uma nova concepção teórica, mas na retomada do discurso comentado como Foucault afirma (2009, p. 26): "o novo não está no que é dito, mas no acontecimento de sua volta", a volta à compreensão presente na escritura, pois o comentário ainda baliza toda a produção acadêmica. Somese a isso o elenco dos quatro princípios reguladores e seus opostos: "o acontecimento à criação, a série à unidade, a regularidade à originalidade e a condição de possibilidade à significação" (FOUCAULT, 2009, p. 54). Pensando a lógica do trabalho acadêmico, como manter a regularidade discursiva e suas respectivas regras de funcionamento e a busca da originalidade?

Outrora dissemos que a estrutura da redação acadêmica pautada na tríade - referencial teórico, dados empíricos e/ou experiência sociais e análise 
de conteúdo - já estava destinada à manutenção/salvação da teoria mesmo que a custo da supressão ou estrangulamento da realidade em benefício da ortodoxia teórica. Nesse sentido, pensamos que a tríade deveria necessariamente ser invertida - o conhecimento da realidade (dados empíricos e/ou experiências sociais) seguido do recurso às teorias que melhor aprouver à análise da realidade e, finalmente, um retorno da reflexão ao espelho do real. O descolar da realidade aconteceria somente à medida que se fizesse necessário o recurso à teoria, porém o centro da escrita não estaria na elaboração do comentário, mas na compreensão da realidade concreta do autor. Deslocar a teoria do primeiro para o segundo plano talvez nos permita compreender o real antes de tentar buscar uma teoria alheia para enquadrá-lo academicamente.

Finalmente, outro aspecto do nosso ceticismo refere-se à função que atribuímos às obras que lemos e àqueles que reconhecemos como autoridades na vida acadêmica. Precisamos reaprender a ler e não apenas ler para reproduzir os textos em linguagem e/ou trabalhos acadêmicos. Meditemos sobre três conselhos nietzschianos (2004, p. 46-47):

O leitor de quem espero algo deve ter três qualidades: ele deve ser calmo e ler sem pressa, não deve sempre privilegiar a si e à sua "cultura", não deve, enfim, esperar por encerrar um quadro de resultados. (...) Um homem como este ainda não desaprendeu a pensar lendo, ele conhece ainda o segredo de ler nas entrelinhas; ele tem inclusive o caráter tão pródigo, que ainda medita sobre o que leu, talvez durante muito tempo depois de ter fechado o livro. E não para escrever um resumo ou ainda um livro, não, somente como tal, para meditar! (...) A terceira e a mais importante de nossas exigências é enfim que, num caso, à maneira dos homens de hoje, ele não coloque, a si e a sua cultura, como medida e critério seguro de todas as coisas.

Definitivamente, produção não rima com ganha pão. O ritmo célere e irrefletido da produção acadêmica talvez seja a verdadeira causa de tão rara originalidade. Não nos damos tempo para meditar sequer o lido e exigimos uma capacidade de pesquisar e produzir resultados e análises a tempo fixo. Temo que enquanto não redescobrirmos um ritmo meditativo de maturação teórica, a academia se reduzirá progressivamente à mera reprodução dos discursos instituídos. O contrário seria redescobrir pessoas que, segundo Nietzsche (2004, 
p. 46) "não podem já habituar-se a calcular o valor de cada coisa pelo tempo economizado ou pelo tempo perdido, (pois) elas têm ainda tempo..."

\section{REFERÊNCIAS}

DERRIDA, Jacques. Margens da filosofia. Trad. J. Costa e A. Magalhães. Campinas: Papirus, 1991.

ECO, Umberto. O pêndulo de Foucault. Trad. I. Barroso. Rio de Janeiro: BestBolso, 2009.

ECO, Umberto. Interpretação e superinterpretação. Trad. M. Salomão. São Paulo: Martins Fontes, 1993.

FIORIN, José Luiz. A pessoa subvertida. Língua e Literatura, oㅡ 21, p. 77-107, 1994/1995.

FOUCAULT, Michel. O que é um autor? Ditos e escritos, vol. 3. Trad. I. A. D. Barbosa. Rio de Janeiro: Forense, 2001.

FOUCAULT, Michel. A ordem do discurso. 19a ed. Trad. L. A. Sampaio. São Paulo: Loyola, 2009.

MARQUES, Lúcio Álvaro. The Jesuit philosophical heritage in Brazil. Massachusetts: Boston College, 2020 (in the press).

MUCHAIL, Salma Tannus. Foucault, simplesmente. São Paulo: Loyola, 2004.

NIETZSCHE, Friedrich. Escritos sobre educação. $2^{\mathrm{a}}$ ed. Trad. N. C. Melo Sobrinho. Rio de Janeiro: PUC-Rio e São Paulo: Loyola, 2004.

PLATÃO. Cartas. $4^{a}$ ed. Trad. C. G. Silva e M. A. Melo. Lisboa: Estampa, 2002. 